\title{
Effect of the temperature on the rheological properties of compound coating
}

\author{
TÍMEA KASZAB $^{1 *}$ (D) LÍDIA BORNEMISZA ${ }^{1,2}$ and \\ KATALIN BADAK-KERTI ${ }^{2}$
}

\footnotetext{
${ }^{1}$ Department of Measurements and Process Control, Faculty of Food Science, Szent Istvan University, 14-16 Somloi str., 1118 Budapest, Hungary

${ }^{2}$ Department of Grain and Industrial Plant Processing, Faculty of Food Science, Szent Istvan University, 29-43 Villanyi str., 1118 Budapest, Hungary
}

\section{CONFERENCE FULL PAPER}

Received: August 13, 2020 • Accepted: October 11, 2020

Published online: November 19, 2020

(C) 2020 The Author(s)

\begin{abstract}
The objective of our experiment was to investigate the rheological properties of a compound coating depending on the pre-treatment temperature regimes.

Compound coating samples were measured at six different temperatures with $2{ }^{\circ} \mathrm{C}$ resolution between 40 and $50{ }^{\circ} \mathrm{C}$. One part of melted samples was measured by RV1 rotational rheometer at the actual melting temperatures and the other part of melted samples was filled into $9 \times 9 \times 9 \mathrm{~mm}$ cubes molds. These cubes were cooled $24 \mathrm{~h}$ in freezer $\left(-18{ }^{\circ} \mathrm{C}\right)$ and next day the samples were warmed to room temperature for 3 hours with different temperature combinations. The solid cubes were measured with Texture Profile Analysis (TPA) test by SMS TA-XTplus Texture Analyzer at room temperature.

Results show the effect of pre-treatment on the viscosity of the coating. Furthermore, significant differences were found among the samples cooled with different cooling methods. Our results stress the importance of the correct handling of the materials for confectioners.
\end{abstract}

\section{KEYWORDS}

compound coating, temperature, rheology, viscosity, TPA

\footnotetext{
*Corresponding author. E-mail: Kaszab.Timea@szie.hu
} 


\section{INTRODUCTION}

Chocolate is an important product of the confectionery industry. The fat in chocolate, the cocoa butter, has quite a few interesting properties, but there are some factors that make it not always suitable. The first is its extremely high and constantly fluctuating world market price, and the second is the problems of its processing and storage (tempering, fat bloom, sugar bloom) (Biczó et al., 2013).

As a result, the use of cocoa butter alternatives in the industry has become increasingly popular. They have similar physico-chemical properties as cocoa butter, but are cheaper and do not require much preparation. During production, some or all of the cocoa butter is replaced by vegetable fat, in which case it can no longer be called chocolate (if the added vegetable fat amount is higher than $5 \%$ based on the total fat content), instead it is called compound coating or simply coating. Coatings can be used further for sweets, baked goods and other snacks (Talbot, 2009).

There are four types of cocoa butter alternatives: Cocoa Butter Equivalents (CBE), Cocoa Butter Improvers (CBI), Cocoa Butter Replacers (CBR) and Cocoa Butter Substitutes (CBS). The CBS coatings have lauric acid content, they are chemically completely different from cocoa butter, thus they express very low $(<5 \%)$ compatibility with cocoa butter (Lipp and Anklam, 1998). CBS fats cannot be blended with cocoa butter because their blend forms an eutectic mixture whose crystallization is unpredictable. These fats solidify in different crystalline structures, therefore these two fat-types are incompatible and it is recommended to use degreased cocoa powder in combination with CBS (Lonchampt and Hartel, 2004).

The steps in the manufacturing process are roughly the same for compound coatings as it is for chocolate, but there are differences in temperature regimes. The main difference is that compound coatings do not require tempering, which makes the production easier. In addition to the chemical composition, the crystallization behavior of fat is influenced also by various dynamic factors, such as cooling rate, mixing and crystallization temperature (Metin and Hartel, 2005).

Important characteristics of both chocolate and coating is their rheological properties such as viscosity and yield stress. Viscosity is on the one hand a phenomenon, internal friction between moving particles, and on the other hand a physical parameter. Because they are not ideal fluids, they have yield stress that require a significant amount of force to start the flow (Beckett, 2008).

The examination of the mechanical parameters of the coatings is also an important point. Compound coatings are solid at room temperature and they must warm up to show flow properties. In melted form they are flowing, and they have no yield stress. According to Foubert et al. (2006) and Gregersen et al. (2015a, 2015b) relationships between microstructure and macroscopic properties in coatings determine their flowing and textural properties (e.g. hardness, brittleness, etc.).

The objective of our experiment was to investigate the rheological properties of a compound coating depending on the pre-treatment temperature regimes in melted and solid condition. Further aim was to predict the highest significant difference among the melted temperatures (40-42-44-46-48-50 ${ }^{\circ} \mathrm{C}$ ) and among thawing methods ( 2 hours refrigerator +1 hour room temperature, 1 hour refrigerator +2 hours room temperature, 3 hours room temperature) based on the determined seven TPA parameters. 


\section{MATERIALS AND METHODS}

\section{Materials}

CBS coating used in the experiments was provided by Göteborgs Food Budapest ZRt. The ingredients of the measured compound coating are following: sugar, partially hydrogenated vegetable fat (palm kernel) CBS fat, low-fat cocoa powder, emulsifiers (sunflower lecithin, polyglycerol polyricinoleate), aroma.

\section{Viscosity measurement of the melted samples}

The compound coating was tempered in Venticell Comfort Line drying chamber (MMM Medcenter Einrichtungen $\mathrm{GmbH}$, Germany) at six different temperatures $40-42-44-46-48-50{ }^{\circ} \mathrm{C}$. The shear stress of the sample was measured with Z10 DinTi type conical end stainless steel cylinder by Haake RotoViscol rotational viscometer at the actual melting temperature, and the viscosity was determined from the ratio of the shear stress and shear rate. The measurement consisted of 3 period with 100-100 s: acceleration section 1-500 1/s, constant speed section at $500 \mathrm{1} / \mathrm{s}$ and deceleration section 500-1 1/s shear rate. The viscosity was determined from the constant speed section of the flow curve at the melting temperatures. Each measured groups consisted of 12 samples $(N=72)$.

\section{TPA measurement of the solid samples}

At each melting temperatures melted samples were filled into $9 \times 9 \times 9 \mathrm{~mm}^{3}$ cubes molds. These cubes were held $24 \mathrm{~h}$ in freezer $\left(-18{ }^{\circ} \mathrm{C}\right)$ and next day the samples were thawed to room temperature for 3 hours with different melting regimes, which were as the following: 2 hours refrigerator +1 hour room temperature, 1 hour refrigerator +2 hours room temperature, 3 hours room temperature. The temperature and the relative humidity were $8.7 \pm 0.6{ }^{\circ} \mathrm{C}$ and $51.1 \pm 9.7 \mathrm{RH} \%$ in the refrigerator and $28.1 \pm 0.3{ }^{\circ} \mathrm{C}$ and $28.4 \pm 0.7 \mathrm{RH} \%$ in the measuring room. The solid cubes were measured with Texture Profile Analysis (TPA) test by TA-XTplus (Stable Micro System, Surrey, UK) Texture Analyzer with P/25 type stainless steel cylinder at room temperature. Test setting were as follows: compression with pre-test speed $2 \mathrm{~mm} / \mathrm{s}$, test speed $1 \mathrm{~mm} / \mathrm{s}$, post-test speed $2 \mathrm{~mm} / \mathrm{s}$, strain $10 \%$, count 2, 200 pps. A $5 \mathrm{~kg}$ load cell was used, and the hardness, adhesiveness, resilience, cohesion, springiness, gumminess and chewiness parameters were determined from the deformation-time curves (Fig. 1). Each measured group consisted of 10 samples $(N=180)$.

\section{Statistical analysis}

The measured rheological properties values were evaluated by SPSS 25.0.2.2 (SPSS, 2018) and R-Studio Version 1.1.414 (R-Studio, 2018). After leaving out the outlier data, a normality test (Kolmogorov-Smirnov and Shapiro-Wilk Test) was run on results of the samples. Two-way ANOVA was used to identify any significant differences between the groups in the case of certain parameters. Where ANOVA indicated TukeyHSD test $(P<0.05)$ was used for detecting the significant differences between the groups (Reiczigel et al., 2014). The thawing temperature were predicted based on the results obtained with mechanical tests parameters by the means of PLS regression (Kvalheim, 2009). PLSR models were built based on hardness, gumminess and chewiness parameters obtained by TA.XTPlus to predict the melting temperature and the thawing methods. 


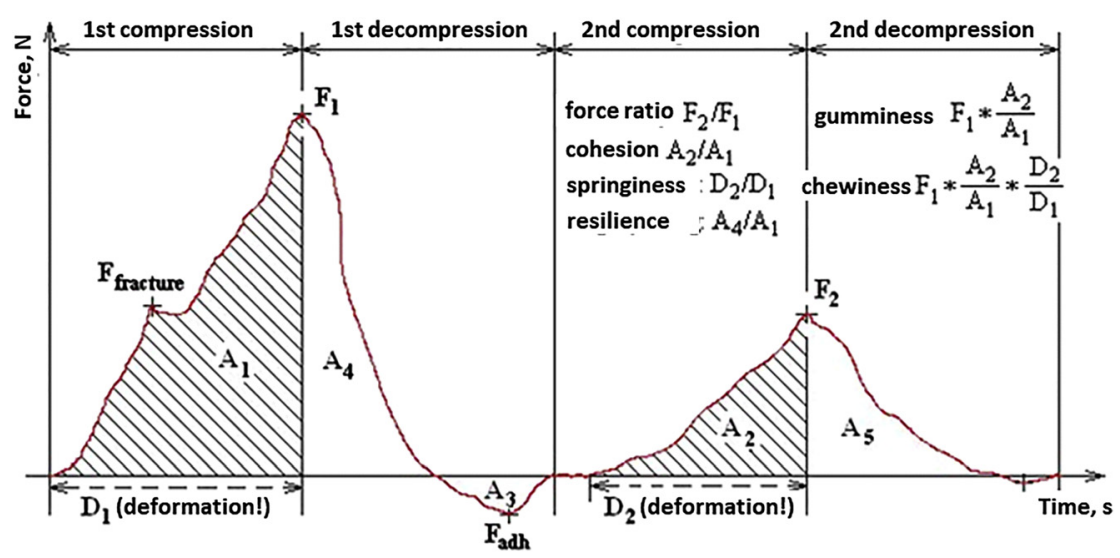

Fig. 1. Typical TPA curve (based on Bourne, 2002)

\section{RESULTS AND DISCUSSION}

Fig. 2 shows the average of the viscosity from the constant speed section of the flow curve at the melting temperatures. The viscosity values for 40 and for $42{ }^{\circ} \mathrm{C}$ were significantly different from each other and from the viscosities measured at the other temperatures. However, there is no significant difference between the viscosities among the groups of $44,46,48$ and $50{ }^{\circ} \mathrm{C}$ melting temperatures. Furthermore, the average and the standard deviation of the viscosity decreases with the increasing temperature, which could be a result of increasing homogeneity in the structure of the samples.

The hardness, adhesion, resilience, cohesion, springiness, gumminess and chewiness parameters were calculated from the deformation-time curve of TPA test. From the rheological parameters the hardness (Fig. 3), gumminess (Fig. 4) and chewiness (Fig. 5) showed significant differences among the sample groups.

The hardness parameter of compound counting cubes showed increasing tendency, proportionally with temperature increase (Fig. 3). The hardness of the sample melted at $50{ }^{\circ} \mathrm{C}$ was

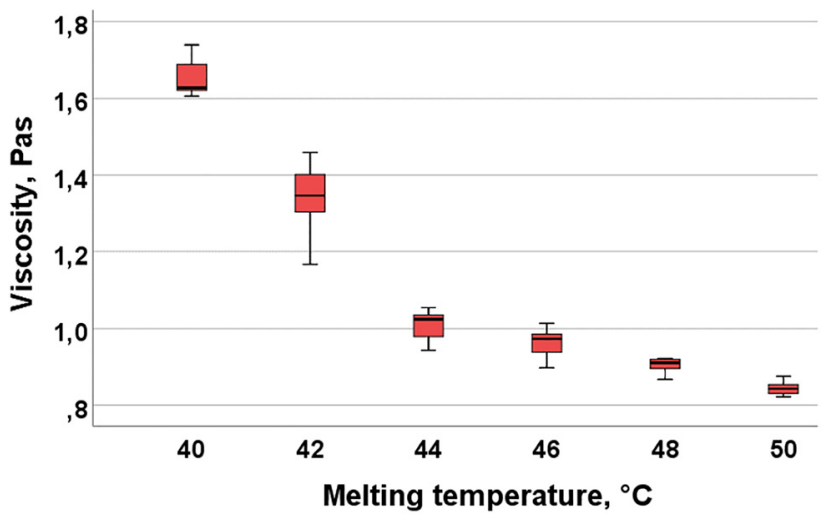

Fig. 2. Viscosity in the function of the melting temperature at $95 \% \mathrm{CI}(N=66)$ 

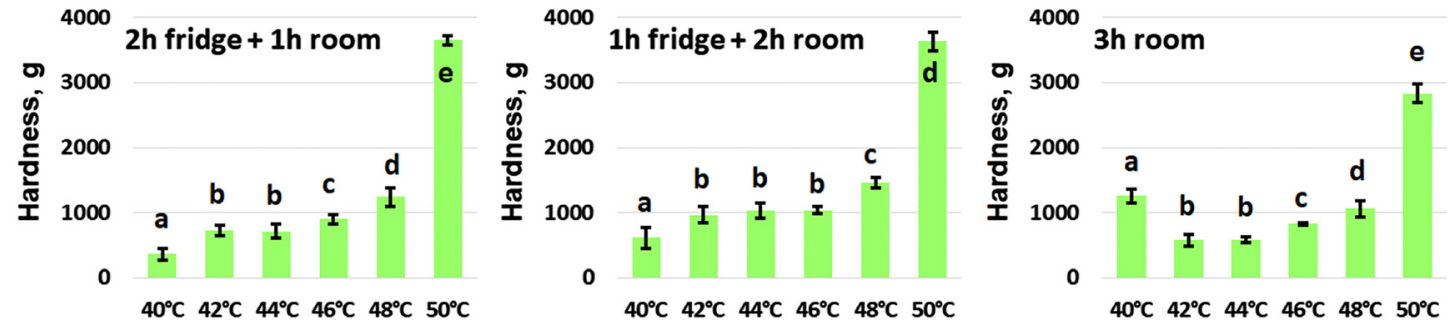

Fig. 3. Significant differences in hardness parameters obtained at given melting temperatures with different thawing conditions $(N=172)(\mathrm{a}, \mathrm{b}, \mathrm{c}, \mathrm{d}, \mathrm{e}$ - significant different samples) 


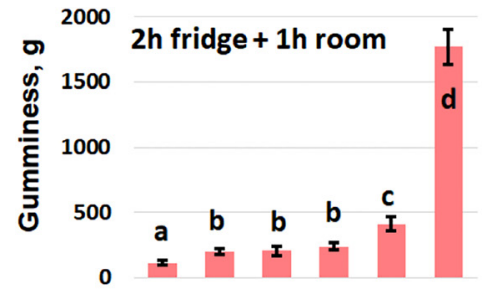

$40^{\circ} \mathrm{C} 42^{\circ} \mathrm{C} 44^{\circ} \mathrm{C} 46^{\circ} \mathrm{C} 48^{\circ} \mathrm{C} 50^{\circ} \mathrm{C}$

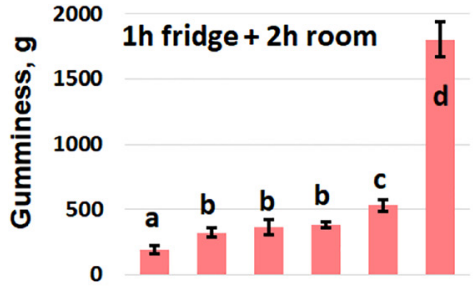

$40^{\circ} \mathrm{C} 42^{\circ} \mathrm{C} 44^{\circ} \mathrm{C} 46^{\circ} \mathrm{C} 48^{\circ} \mathrm{C} 50^{\circ} \mathrm{C}$

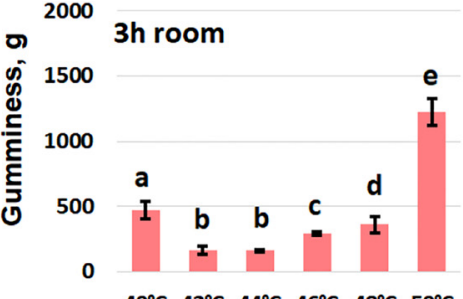

$40^{\circ} \mathrm{C} 42^{\circ} \mathrm{C} 44^{\circ} \mathrm{C} 46^{\circ} \mathrm{C} 48^{\circ} \mathrm{C} 50^{\circ} \mathrm{C}$

Fig. 4. Significant differences in gumminess parameters obtained at different melting temperatures with various thawing system $(N=170)$ and $(a, b, c$, d, e - significant different samples) 


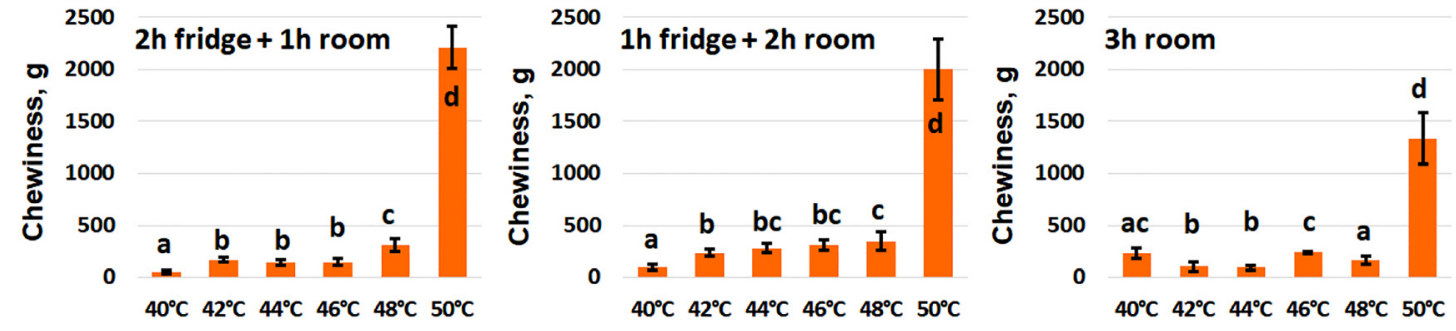

Fig. 5. Significant differences in chewiness parameters obtained at different melting temperatures with various thawing system $(N=165)$ and $(\mathrm{a}, \mathrm{b}, \mathrm{c}$, d - significant different samples) 

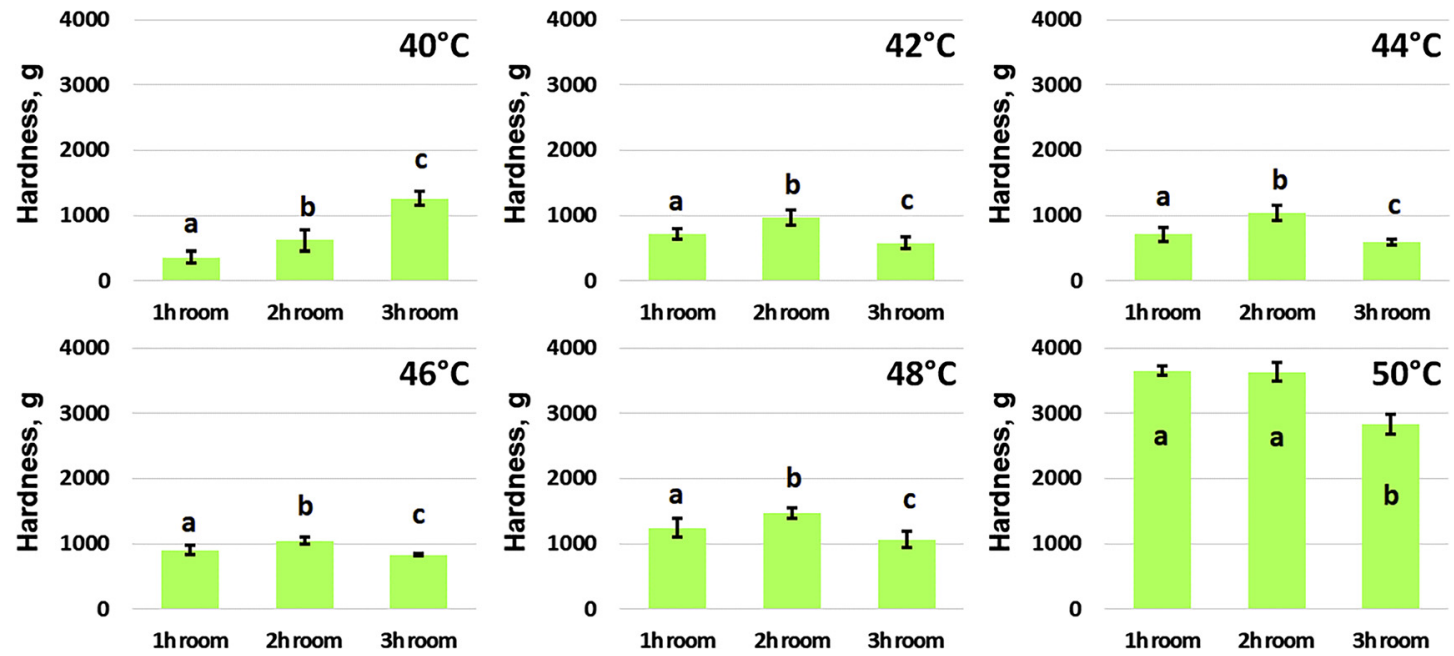

Fig. 6. Significant differences in hardness parameter among the thawing conditions of the differently melted samples $(N=172)(\mathrm{a}, \mathrm{b}, \mathrm{c}-$ significant different samples) 

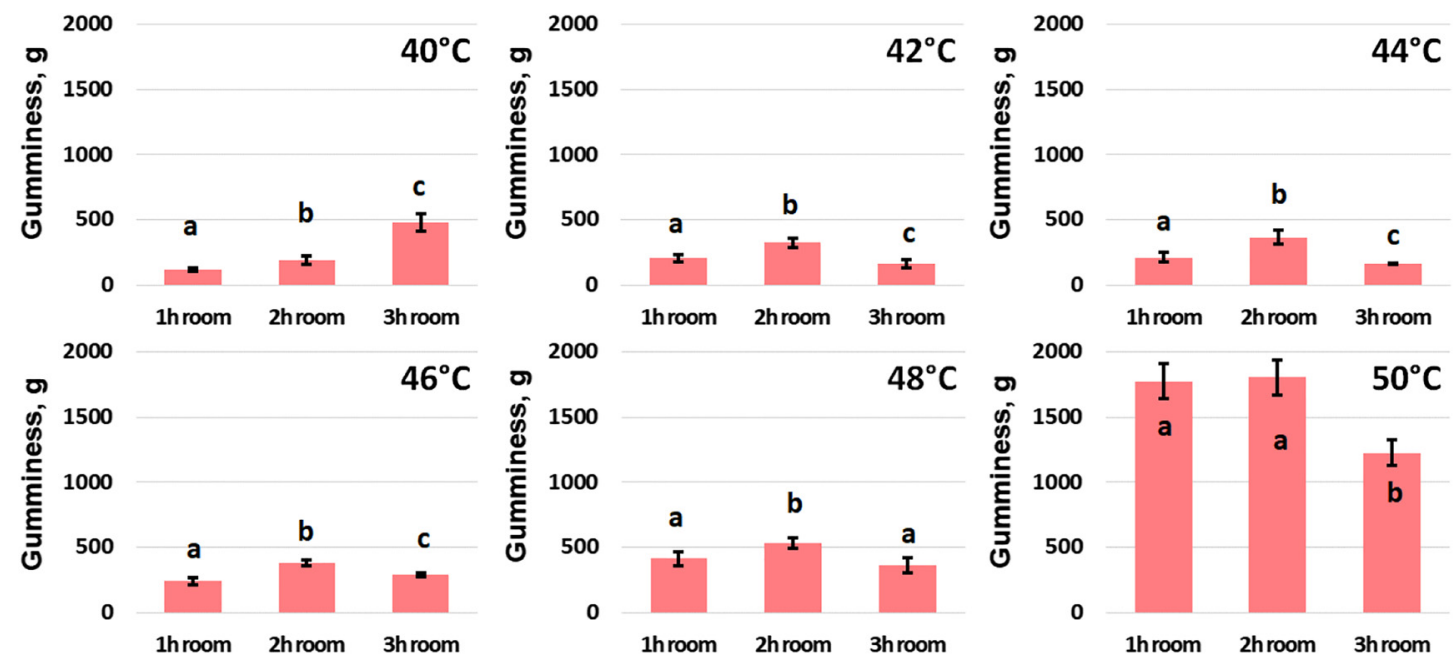

Fig. 7. Significant differences in gumminess at various thawing conditions of the melted-frozen samples $(N=170)(a, b, c-s i g n i f i c a n t ~ d i f f e r e n t)$ 

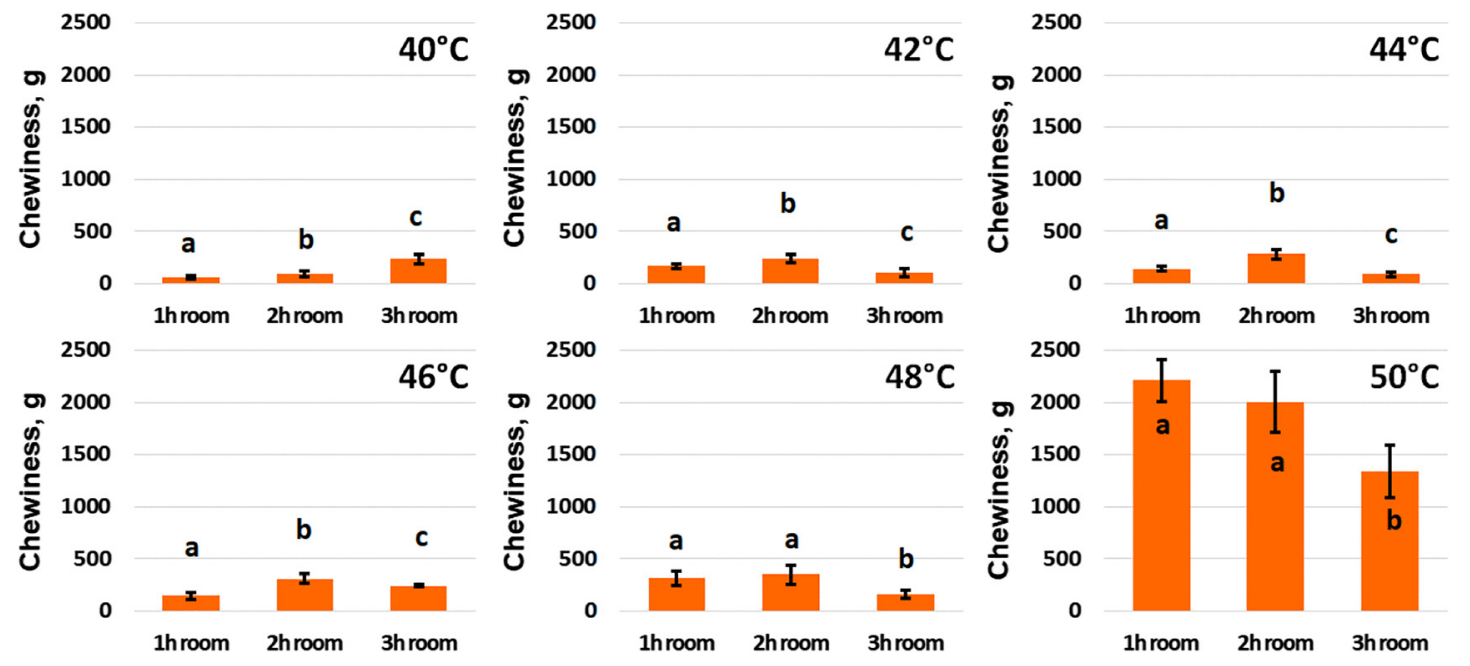

Fig. 8. Significant differences in chewiness at various thawing conditions of the differently melted samples $(N=165)(a, b, c-s i g n i f i c a n t$ different $)$ 
Table 1. PLS calibration and cross-validation (leave one out (LOO)) to predict the properties of melting temperature and thawing conditions based on the results of the hardness, gumminess and chewiness

\begin{tabular}{|c|c|c|c|c|c|}
\hline \multirow[b]{2}{*}{ Property } & \multirow[b]{2}{*}{ LV (number) } & \multicolumn{2}{|c|}{ Calibration } & \multicolumn{2}{|c|}{ Cross validation } \\
\hline & & $\mathrm{R}^{2}$ & RMSEC $^{*}$ & $\mathrm{R}^{2}$ & RMSEP $^{* *}$ \\
\hline Melting temperature $^{\mathbf{A}}$ & 3 & 0.5207 & 2.361 & 0.5106 & 2.386 \\
\hline Melting temperature ${ }^{\mathbf{B}}$ & 2 & 0.6016 & 2.153 & 0.5925 & 2.177 \\
\hline Melting temperature ${ }^{\mathrm{C}}$ & 2 & 0.5912 & 2.181 & 0.5811 & 2.208 \\
\hline Thawing condition ${ }^{\mathbf{A}}$ & 3 & 0.1317 & 0.7630 & 0.1046 & 0.7748 \\
\hline Thawing condition ${ }^{\mathbf{B}}$ & 2 & 0.06938 & 0.7899 & 0.04139 & 0.8017 \\
\hline Thawing condition ${ }^{\mathrm{C}}$ & 2 & 0.09389 & 0.7794 & 0.0686 & 0.7902 \\
\hline
\end{tabular}

${ }^{*}$ Root mean square error of calibration.

${ }^{* *}$ Root mean square error of prediction.

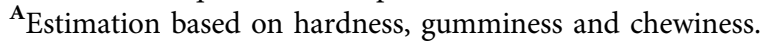

${ }^{\mathbf{B}}$ Estimation based on hardness and gumminess.

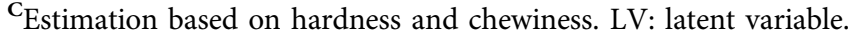
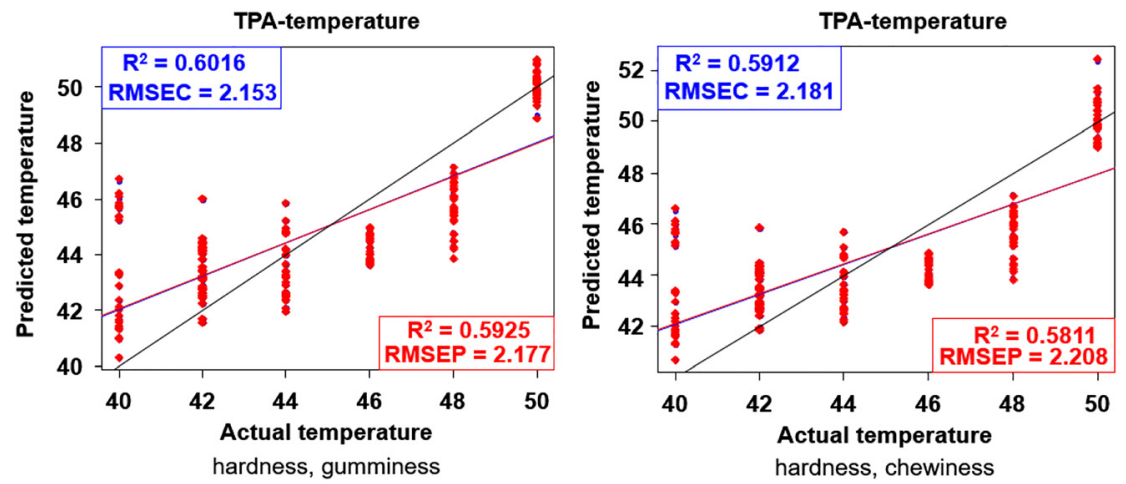

Fig. 9. PLSR Results of the prediction of the melting temperature of measurement based on the hardness, gumminess and chewiness

significantly higher - about twice as high as the value obtained at the other melting temperatures. Hardness parameters of samples melted at temperatures 42 and $44{ }^{\circ} \mathrm{C}$ were not differing significantly from each other.

The gumminess and chewiness (Figs. 4 and 5) increased with the increase of the melting temperature. The values of these parameters are also extremely high after melting at $50{ }^{\circ} \mathrm{C}$ temperature. Significant difference was found between the values of these parameters for samples melted at various temperature, but there was no significant difference in these parameters of samples melted at $42-44{ }^{\circ} \mathrm{C}$.

TPA rheological parameters of the samples were statistically analyzed grouped by the thawing methods, too. Figs. 6, 7 and 8 illustrate these results at various melting temperatures. Significant differences were found among the hardness parameters of cubes thawed with various procedure. This significant difference can be observed for almost all samples except the samples 
melted at $50{ }^{\circ} \mathrm{C}$. However, the samples thawed only at room temperature were significantly different from the samples which had been thawed partially in the refrigerator (Fig. 6).

In the case of the gumminess and chewiness (Figs. 7 and 8) except for $48{ }^{\circ} \mathrm{C}$ samples the results are the same. The groups are separated well by the used melting temperatures. Furthermore, significant difference was found between the thawing conditions, the samples thawed only at room temperature are significantly distinguished.

The melting temperature and thawing conditions were used in an estimation model based on the hardness, gumminess and chewiness parameters of TPA curve measured by Texture Analyzer. Results were used in the PLS regression (Table 1). Acceptable correlation was found between the estimated and measured parameters based on the correlation of the cross - validation at hardness, gumminess and chewiness, the estimation showed the highest correlation based on the hardness and gumminess.

Fig. 9 shows the results of the prediction of the melting temperature and thawing conditions properties of the samples based on the data of experiment. The diagrams contain also the parameters of calibration and leave one out (LOO) cross - validation.

\section{CONCLUSION}

The objective of our experiment was to investigate the rheological properties of a compound coating depending on the pre-treatment temperature regimes in melted and solid conditions. Further aim was to predict the melted temperatures and thawing conditions based on those TPA parameters which showed the highest significant different.

From the determined rheological parameters the hardness, gumminess and chewiness showed the strongest significant differences among the samples. These parameters are suitable to describe the differences between the groups based on the melting temperatures and the thawing conditions. The hardness, gumminess and chewiness showed the same results at all melting temperatures. The maximum melting temperature - recommended by the manufacturer - is 50 ${ }^{\circ} \mathrm{C}$. It can be assumed that the coating mass has a different behavior at this temperature and its spectacular effect can be seen in the parameters examined during the experiment. This assumption is confirmed by the BC Cook Articulation Committee (2015) that temperatures above $50{ }^{\circ} \mathrm{C}$ can be a problem for coatings because the crystalline structure formed earlier will be destroyed and the viscosity of the mass will be reduced, thereby impairing the coating ability.

\section{REFERENCES}

BC Cook Articulation Committee. (2015). Understanding ingredients for the Canadian baker. BC Campus, Victoria, BC. Retrieved from https://opentextbc.ca/ingredients/. ISBN: 978-1-7753524-5-7.

Beckett, S.T. (2008). The science of chocolate, 2nd ed. Formerly Nestle Product Technology Center, York, UK. ISBN: 978-0-85404-970-7.

Biczó, V., Fekete, A., and Scherer, R. (2013). Influence of composition and storage conditions on chocolate hardness and heat resistance. Progress in Agricultural Engineering Sciences, 9(1): 55-73. http:// akademiai.com/doi/abs/10.1556/Progress.9.2013.3. 
Bourne, M.C. (2002). Food texture and viscosity, concept and measurement, 2nd ed. Academic Press, San Diego, CA, p. 400 pp. 51, 97-98., 113-114., 178-185., 198., 235-242. http://dx.doi.org/10.1016/b978012119062-0/50004-8.

Foubert, I., Vereecken, J., Smith, K.W., and Dewettinck, K. (2006). Relationship between crystallization behavior, microstructure, and macroscopic properties in trans containing and trans free coating fats and coatings. Journal of Agricultural and Food Chemistry, 54: 7256-7262, https://doi.org/10.1021/ jf060225e.

Gregersen, S.B., Miller, R.L., Hammershøj, M., Andersen, M.D., and Wiking, L. (2015a). Texture and microstructure of cocoa butter replacers: Influence of composition and cooling rate. Food Structure, 4: 2-15, https://doi.org/10.1016/j.foostr.2015.03.001.

Gregersen, S.B., Povey, M.J.W., Kidmose, U., Andersen, M.D., Hammershøj, M., and Wiking, L. (2015b). Identification of important mechanical and acoustic parameters for the sensory quality of cocoa butter alternatives. Food Research International, 76: 637-644, https://doi.org/10.1016/j.foodres.2015.07.022.

Kvalheim, O.M. (2010). Interpretation of partial least squares regression models by means of target projection and selectivity ratio plots. Journal of Chemometrics, 24: 496-504.

Lipp, M. and Anklam, E. (1998). Review of cocoa butter and alternative fats for use in chocolate-part A. Compositional data. Food Chemistry, 62: 73-97, https://doi.org/10.1016/S0308-8146(97)00160-X.

Lonchampt, P. and Hartel, R.W. (2004). Fat bloom in chocolate and compound coatings. European Journal of Lipid Science Technology, 106: 241-274, https://doi.org/10.1002/ejlt.200400938.

Metin, S. and Hartel, R.W. (2005). Crystallization of fats and oils. Baileys Industrial Oil and Fat Products, 1: 45-76.

Reiczigel J., Harnos A., and Solymosi N. (2014). Biostatisztika nem statisztikusoknak, javitott utánnyomás. Pars Kft., Budapest.

Talbot, G. (2009). Compound coatings. In: Science and technology of enrobed and filled chocolate, confectionery and bakery products. Elsevier, pp. 80-100.

Open Access. This is an open-access article distributed under the terms of the Creative Commons Attribution 4.0 International License (https://creativecommons.org/licenses/by/4.0/), which permits unrestricted use, distribution, and reproduction in any medium, provided the original author and source are credited, a link to the CC License is provided, and changes - if any - are indicated. (SID_1) 